\title{
Artificial intelligence and the question of being
}

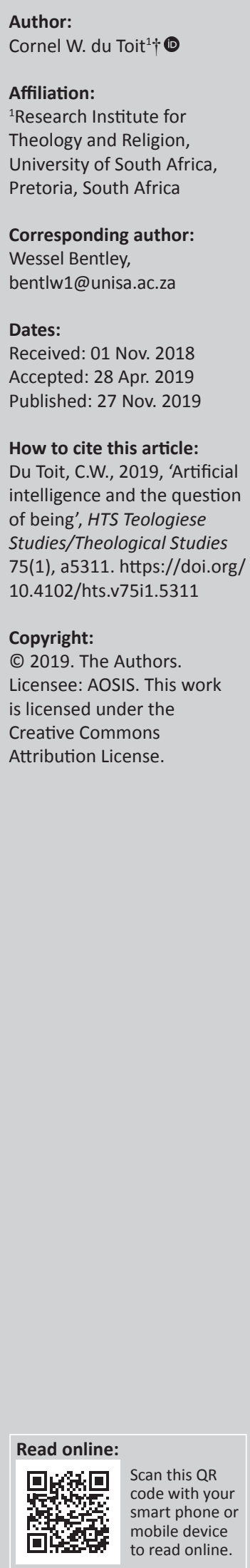

Technology is part of all life forms. This does not mean that all technology is beneficial for life. Technological evolution in the human sphere holds promises to attain the status of singularity. This identifies the so-called Fourth Industrial Revolution. What is at stake includes the emergence of intelligent and conscious super computers and robots, conscious materialism, the possibility of human immortality and the emergence of the trans-human. In the ambit of a new artificial environment in which humans will live, the question of being must be addressed again. How will all of this affect the question of being human and new conceptions of 'self'? To what extent will the possibility of techno-religion replace traditional religions with its promise of eradicating poverty, illness and death? This article focuses on these and related issues to identify possibilities of a new artificially envisaged lifestyle.

Keywords: Artificial intelligence; Fourth Industrial Revolution; Being and artificiality; Technoreligion; Human-machine interaction; Conscious materialism; Spiritual materialism.

\section{Introduction}

Consciousness and being will be discussed in this article against the horizon of advanced technology in the form of Artificial Intelligence (AI) and the way it affects human life and human values. All species are one with their environment.

A dynamic reciprocal relationship exists between species and environment. Humans are rapidly changing their (cultural) environment, which is increasingly determined by AI. We presently experience the rapid evolution of computers and the increased possibility of human-machine interaction. It will change human's self-perception, the experience of reality, value systems and style of living. We are indeed not victims of this inevitable evolution because it is driven by ourselves. Yet, the way these developments will unfold is not entirely clear nor is it democratic. It is determined by a few big corporations, but will determine the life of all. Billions of dollars are invested in research and new innovations and investors expect good returns on their money. Much of AI developments are still in an embryonic phase, but hold promises to become generally available soon. Although we may doubt the timeline of these innovations and discard many predictions as futuristic dreams, much of what is on the table will probably soon materialise. This necessitates earnest thinking about possible consequences and how it will affect the very nature of what it means to be human.

The topic of AI has occupied the philosophy of consciousness since early modernity - it did not first become virulent with the emergence of computers (Gabriel 2017:86). The development of AI brings the question of being to the fore in the mode of being and artificiality - the relationship between being, non-being, reality and illusion. If machines become 'intelligent', will they also be conscious? This brings technological consciousness and conscious materialism into focus. To what extent will human-machine interaction change what it means to be human? We attempt to address these issues here.

'Artificial intelligence' is a generic term referring to machines, robots and computers that can perform tasks that we consider intelligent. But we do not really know what machine intelligence is and is it really intelligence? Human consciousness is embedded in language, logic, enhanced memory and significant processing power. Kurzweil (2005:149) mentions that the human brain as a whole operates with up to a hundred trillion computations being carried out simultaneously. This ability helps us to recognise patterns, think metaphorically (see one thing in terms of another) and create new ideas. Machine processing power may eventually far exceed that of humans; however, they will lack the uniqueness of the human body without which mind and consciousness would not be what it is.

Note: SASRF 2019, sub-edited by Cornel du Toit (University of South Africa) and Wesel Bentley (University of South Africa). $\dagger, 1953-2019$. 
Real intelligence includes consciousness and machine consciousness is not yet a reality. Should machines become conscious, intelligent and autonomous entities with something like self-consciousness, we would have a totally new kind of being to deal with. Machine 'consciousness' would be a total different kind of consciousness than human consciousness.

\section{The Fourth Industrial Revolution and artificial intelligence}

We are presently entering the Fourth Industrial Revolution. The First Industrial Revolution usually refers to application of steam power to industry; the Second Industrial Revolution refers to the invention and application of electricity; the Third Industrial Revolution refers to the introduction of electronics and information technology to industry; and the Fourth Industrial Revolution refers to advanced technology that fuses biotic and abiotic, conscious and non-conscious spheres. Therefore, it is a generic term that includes more than artificially intelligent machines. It includes cyborg technology that aligns prostheses and electronically enhanced technology with the human brain and body. Artificial limbs, visual and hearing devices and the communication between the human brain and artificial devices are examples of Fourth Industrial Revolution.

The benefits for human health are impressive, namely, think of genetic technology, bioinformatics and integrative genomics, genetic repair and replacement procedures Clustered Regularly Interspaced Short Palindromic Repeats (CISPR). In molecular biology, biochips are envisaged that are essentially small laboratories that can perform numerous simultaneous biochemical reactions. Biochips enable researchers to quickly screen large numbers of biological data to monitor health, diagnose disease and identify phages (the natural enemy of bacteria that can help control dangerous pathogens).

Advances in communication technology, AI, quantum and bio-computing, robotics, biotechnology, bionic technology and genetic technology, the annihilation of illnesses and ageing, self-directed vehicles, three-dimensional (3D) printing, nanotechnology, material science, and enhanced energy storage, to name but a few, are on the agenda of the Fourth Industrial Revolution.

It will introduce a new phase in the labour market and would significantly change liberal capitalism. Most people may be unemployed, but new job opportunities will arise as is the case with the introduction of new technologies. Some people will be dependent on government grants and will develop a lifestyle outside the labour market. It may also render humans in comparison to machine abilities as 'useless' (Harari 2015:409ff.).

The possibilities of billions of people connected by mobile devices, with unprecedented processing power, storage capacity and access to knowledge, are unlimited. These possibilities will be multiplied by emerging technology breakthroughs in fields such as robotics, AI, nanotechnology, quantum computing, biotechnology, the Internet of Things (IoT), 3D printing and autonomous vehicles.

Artificial intelligence will change the human environment as we know it. It has already affected all levels of society, from economics and the labour market to politics and the military. It will impact human relationships on all levels and open up a new dimension of human-machine interaction. It will indirectly impact human health and longevity, will affect genetic repair and mutation, and will introduce new bionic possibilities.

It will introduce new forms of attachment and interaction with non-living machines that will impact the way we usually interact with fellow humans. The crucial question, however, is whether these machines will really be intelligent. Intelligence is simply more than machines fulfilling tasks, solving problems and performing tedious tasks that were previously assigned to humans.

Three levels are envisaged: Artificial Narrow Intelligence (ANI) or week AI; Artificial General Intelligence (AGI) or 'strong' AI that refers to self-thinking, autonomous machines; and Artificial Super Intelligence (ASI) that refers to machines that far exceed human abilities.

Artificial narrow intelligence or weak AI refers to typical tasks performed by computers today. This can be distinguished from AGI, where computers are really intelligent on a level that imitates human intelligence. Artificial narrow intelligence that represents our current AI technology is data-dependent and is programmed to perform one specific task at a time. Being programmed to perform a task excludes any form of self-thinking or autonomous decision-making. It stays within the parameters of the programmed tasks whether it is dealing with human inquiries (Siri), playing chess, analysing the weather, driving cars, performing translation services, doing face and other forms of recognition, analysing data and so on. These systems operate at a much quicker pace than humans can. It takes on much of the menial work humans presently do, is accurate and fast.

To a high degree, humans are programmed also. Genetically, we are programmed to operate in a certain way. Culturally, we think within a specific language, community and education system with its paradigms, methods and epistemologies. We feel free to improvise within these parameters, but there are limits to this freedom. Are programmed computers so far away from the freedom and choices that humans have? The answer is probably 'no'. In the case of humans, emotion comes into the equation.

Freedom is strongly linked to our emotions. To be free is to feel free. You may be free, but if you do not feel free, your experience is one of being trapped in an optionless situation. More complex aspects come into play, like fear, love, dependence, jealousy, aversions, avarice, hope, ambition and 
so on. Some of these aspects are seen as negative and may be interpreted by humans as sin, or pathology. Computers do not have emotion - not yet - and it is probably too complex to simply programme these features into machines. Upshot is that freedom cannot be thought without these factors and higher intelligence without freedom cannot be seen as 'real' intelligence.

The challenge is to move beyond the confines of programmed operations and to learn machines to interact with the outside environment. Similar to humans, machines need to sense and interpret the outer environment. This requires instruments that emulate human senses of vision, hearing, touch, smelling and even tasting. These senses are marked by individuality, taste and aspects related to qualia. All this pertains to the organic whole of perception and the notion of doxic objects in the real world that must be recognised, identified, interpreted and interacted with. This is a huge challenge because a machine must be able to read and understand not only dead objects in its environment, but also the nature, identity, needs and desires of other machines, animals and humans. With this ability comes the task of judgement. One has to interpret a situation, evaluate and select the apt response in the light of one's knowledge and do all of this intuitively. Artificial narrow intelligence systems act as the building blocks of more intelligent AI that we might encounter in the near future.

Artificial general intelligence or 'strong' AI refers to machines that are conscious, sentient and driven by emotion and selfawareness. How this level of autonomy will be attainable is still uncertain and, if possible, lies quite far in the future. When machines and robots have the ability to closely imitate humaneness, humans may easily be fooled to imagine that they are interacting with fellow humans instead of machines. Artificial general intelligence machines are expected to be able to reason, solve problems, make judgements when clear-cut options are not available, plan, learn, integrate prior knowledge in decision-making, and be innovative, imaginative and creative.

Machines can process data faster than humans. However, humans have the ability to think abstractly, strategise and tap their memory to make informed decisions or come up with creative ideas. This makes humans superior to machines. However, for machines to achieve true humanlike intelligence, they require a human physical makeup and psychological factors that are not even transparent to us.

\section{Artificial super intelligence}

Oxford philosopher Nick Bostrom (2014:26) defines 'super intelligence' as 'any intellect that greatly exceeds the cognitive performance of humans in virtually all domains of interest'. Artificial super intelligence will surpass human intelligence in all aspects - from creativity to general wisdom to problemsolving. Machines will be capable of exhibiting intelligence that we have not seen in the brightest among us. This is the type of AI that many people are worried about, and the type of AI that people like Elon Musk think will lead to the extinction of the human race.

\section{The Gartner Company as an example of an artificial intelligence driving force}

Gartner, founded in 1979, has over 15000 employees located in more than 100 offices around the world. It is a global research and advisory firm providing help for leaders in information technology (IT), Finance, human resources (HR), Customer Service and Support, Legal and Compliance, Marketing, Sales and Supply Chain functions across the world. Its research services clients from large corporations, government agencies, technology companies and the investment community. Its client base consists of 12000 organisations in over 100 countries.

Gartner issued its Hype Cycle for emerging technologies selecting a set of 35 emerging technologies and trends (Gartner 2018) (see Figure 1).

Gartner has selected the following leading technologies, namely, AI Platform as a Service (PaaS), AGI, Autonomous Driving (levels 4 and 5), Autonomous Mobile Robots, Conversational AI Platform, Deep Neural Nets, Flying Autonomous Vehicles, Smart Robots and Virtual Assistants.

Examples of the emergence of Virtual Personal Assistants (VPAs) can be found in Amazon Echo and Google Home. Technologies like Blockchain, Blockchain for Data Security, Digital Twin, IoT Platform and Knowledge Graphs represent the so-called ecosystem-enabling platforms that lay the ground for new business models that represent the bridge between humans and technology.

Significant growth is predicted for the IoT enabled by the launch of fifth-generation (5G) network technology. It provides a significant increase in the speed and responsiveness of wireless networks. Several global leading Communications Service Providers (CSPs) have begun testing 5G. It is expected that the first commercial services will launch in the next year or two. The IoT is the network of physical devices, vehicles, home appliances and other items embedded with electronics, software, sensors, actuators and connectivity that enables these things to connect and exchange data, creating opportunities for more direct integration of the physical world into computer-based systems, resulting in efficiency improvements, economic benefits and reduced human exertions. Silicon anode batteries represent the nextgeneration lithium-ion batteries making use of silicon anodes that utilise silicon nanotubes, which produce significantly higher energy storage and longer battery life. 


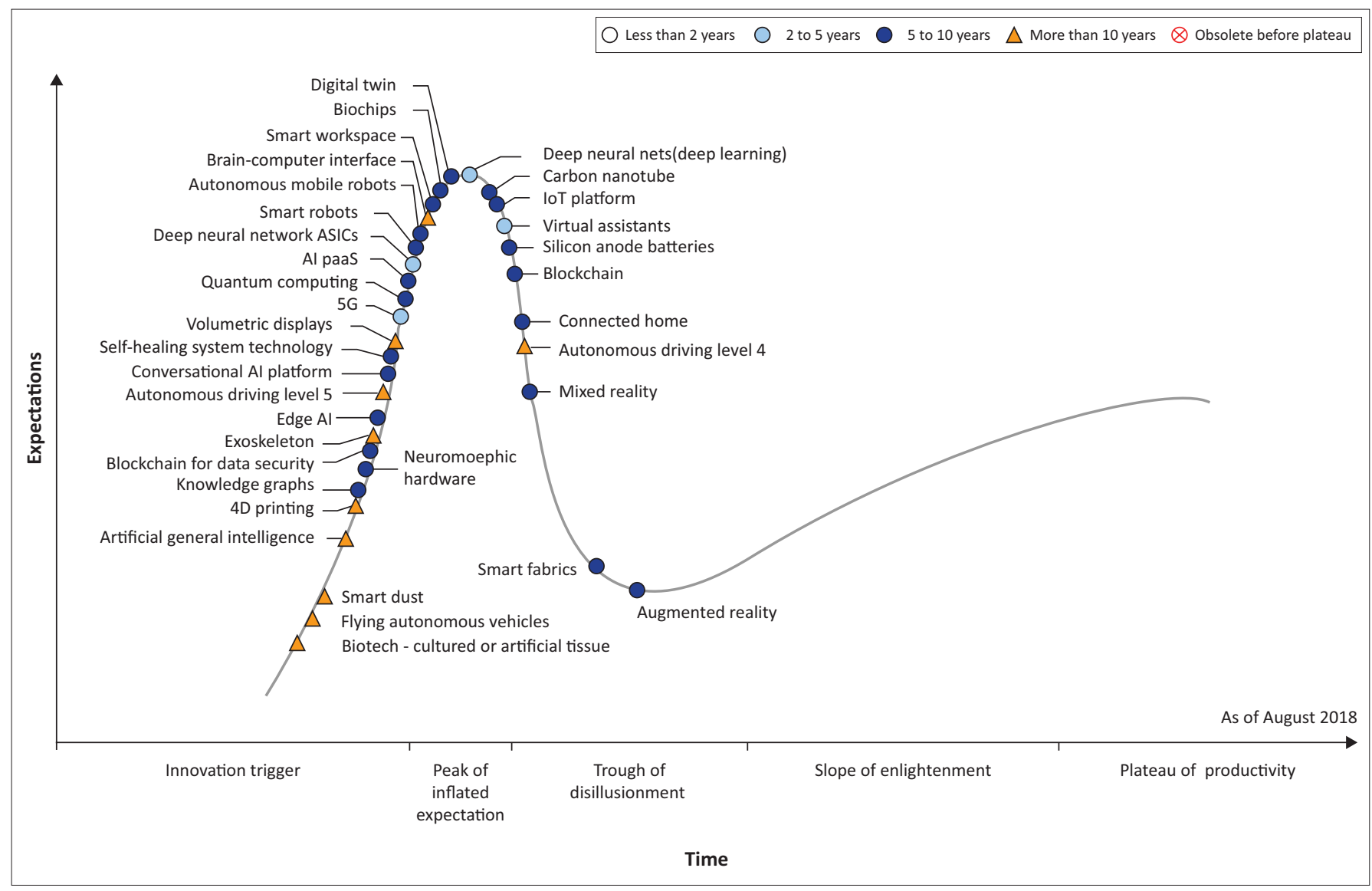

Source: Gartner, 2018, Gartner identifies five emerging technology trends that will blur the lines between human and machine, viewed 20 August 2018, from https://www.gartner.com/en/ newsroom/press-releases/2018-08-20-gartner-identifies-five-emerging-technology-trends-that-will-blur-the-lines-between-human-and-machine

FIGURE 1: Expected technological progress over time.

Gartner (2018) avers that over the next decade, humanity will begin its 'transhuman' era:

Biology can then be hacked, depending on lifestyle, interests and health needs. Biohacking ${ }^{1}$ falls into four categories: technology augmentation, nutrigenomics, experimental biology and grinder biohacking. Biohacking includes technology augmentation, nutrigenomics, experimental biology and grinder biohacking making use of Biochips, Biotech, Cultured or Artificial Tissue, Brain-Computer Interface, Augmented Reality, Mixed Reality ${ }^{2}$ and Smart Fabrics. ${ }^{3}$ However, questions remain about how far society is prepared to accept these kinds of applications and what ethical issues they create. (n.p.)

Artificial intelligence is money-driven. Venture capital is merely readily available than ever before and taps into the vast resources of human creative capital. The increasing global interactivity of humans through the net evokes hidden

1.This includes Grinder biohacking, namely, grinders are people who apply the hacker ethic to improve their own bodies with do-it-yourself cybernetic devices or introducing chemicals into the body to enhance or change their bodies' functionality. Many grinders identify with the biopunk movement, open-source transhumanism and techno-progressivism. The Grinder movement is strongly associated with the body modification movement and practises actual implantation of cybernetic devices in organic bodies as a method of working towards transhumanism.

2.Window's 'Mixed Reality' is a mixed reality platform introduced as part of the Windows 10 operating system, which provides holographic and mixed reality experiences with compatible head-mounted displays. Volumetric displays create visual representations of objects in three dimensions, with an almost $360^{\circ}$ spherica viewing angle in which the image changes as the viewer moves around.

3.Smart fabrics, namely, electronic textiles, also known as smart garments, smart clothing, smart textiles or smart fabrics, are fabrics that enable digital components such as a battery and a light (including small computers), and electronics to be embedded in them. ideas and brings all people potentially into the centre of development. Billions of dollars are invested in various corporations that must come up with profitable results. Consequently, big corporations invest millions of dollars in research promising attractive profits. Accenture, Gartner, IMB, Microsoft, Google, Tesla Motors and Space X, to name but a few, are spearheading the process.

\section{Towards techno-religion?}

We are entering the age of technological Messianism that includes most promises contained in Christian Messianism. Kurtzweil's 2005 book The Singularity Is Near echoes the words of John the Baptist in Matthew 3:2 '...the Kingdom of Heaven is near'. The present views of AI seem to selectively replace the tenets of traditional religion. Through machinehuman interface, humans can become more autonomous and independent, possibly immortal, transcending the confines of time and space. Ignorance may be overcome by acquiring a god-like mind through human-machine interface. This may replace traditional Christian notions like belief in and dependence on God, the experiencing of creatureliness and sin and the longing for salvation. Humans become their own creators. The human individual can choose his or her own virtual paradise and enjoy a life of constant recreation without the need to labour and fulfil all the desires. 
Techno-religion is a religion that entails the possibility of an artificial 'God'. The main functions of its 'God' will be fulfilled by machines, namely, they will have god-like power, are seemingly omnipresent, know everything, are able to watch our every movement as Big Brother, will make us totally dependent on them, can provide the salvation we need, will fulfil all our needs, have power over life (and death) and will stand in a relationship with us.

The security offered by technological advances contributes towards the secularisation of predestination (technology determines our lives in the minutest detail); communication technology gives a new meaning to omnipresence; and consumerism affects our relationship with nature. It is clear that present-day technologies already fulfil many of these functions.

With AI humans are entering the domain of the gods. In Genesis 1:26 (King James Version) God said:

Let us make man in our image and likeness and let him have dominion over the fish of the sea, and over the birds of the air, and over cattle, and over all the earth, and over every creeping thing that creeps upon the earth.

God gave man dominion but restricted it to dominion over creation. Humans wanted more. They desired the heavenly realm of the gods. They wanted to become sicut Deus, like their maker, which means dominion over God. With AI, human dominion enters a new stage. And man said:

Let us make machines in our image and likeness and let them have dominion over all the menial tasks we do not want to do, process difficult calculations and give us access to vital statistical information; let them help us develop the best military hardware and give us god-like influence in the social sphere and increase our profits.

But similar to humans machines may also want to revolt and become like their creators (sicut homo), which does not exclude dominion over their creators. The fear of humans becoming enslaved by their own inventions is the theme of many science-fiction movies. Artificial intelligence is the outcome of the evolution of technology. It may overturn the traditional subject-object relationship humans have with machines and replace humans as subjects. Machines will decide what we can do, how we live and what programmes we use, and determine our movements and boundaries. This will change our experience of reality, influence our values and alter our style of living. To critique technology is always ambiguous because we are not prepared to live without its advantages. We have become totally dependent on technology. Ironically, this total dependence on technology creates for many a feeling of total independence and deliverance from transcendent bonds.

\section{Big data and Dataism}

Big data represented by large data sets is complex and difficult to interpret. If it is sufficiently large, one can find almost anything one seeks lurking within. It will always contain more information within than what we can extract. '... big data have a number of inherent characteristics that make them qualitatively different from previous forms of data' (Fuller 2017:184). Examples of big data are the information generated by the Big Hadron Collider (CERN), the Sloan Digital Sky Survey, data from online shopping, information generated by Global Positioning Systsems (GPS) systems, medical records and the like (see Fulller 2017:183). Because it is so difficult to understand and interrogate, Fuller (2017:182) judges that theologians with good hermeneutical skills may aid in the process.

Dataism is the name Harari (2015:409) gives to the new God of the 21st century. If everything is data, then data is God. Computers work with big data and intelligent machines will have access to it. Big data is characterised by volume, variety and velocity (Fuller 2017:182). Humans cannot compete with any intelligent machine that operates with big data. This seems all rather reductionistic. Data is not everything and definitely not God.

In Harari's terms, data will fulfil the role of God redeeming humanity. It will come to the fore in techno-religions that may conquer the world by promising salvation through algorithms and genes. He distinguishes two possible forms of techno-religions: techno-humanism and data religion. Techno-humanism considers Homo sapiens to have run its historical course and attained its apex. '...we should therefore use technology in order to create Homo deus - a much superior human model' (Harari 2015:410). This superior model will have enhanced mental and physical abilities. Homo deus can become lord of the galaxy with the help of genetic engineering, nanotechnology and brain-computer interfaces (Harari 2015:410-411). ${ }^{4}$ Data religion focuses on data processing. Dataism considers biochemical and electronic algorithms as founded on the same mathematical laws, and '...thereby collapses the barrier between animals and machines' (Harari 2015:428).

Harari (2015:429) sees organisms as algorithms and giraffes, tomatoes and human beings, simply as different methods for data processing. According to him, this is the current scientific dogma. Dataism in this sense collapses the barrier between animals and machines and expects to eventually outperform biochemical algorithms (Harari 2015:428). Harari (2015:440443 ) interprets the evolution of human history in terms of the increase in data-processing abilities. It is based on four basic methods: increasing the number of professors, increasing the variety of processors, increasing the interconnection between processors and increasing the freedom of movement between these processors. Applied to human evolution, the increase of humans represents the increase in processors; as humankind is spread out over the world and is diversified, they increase the variety of processors; with globalism and

4.For an analogy between computing and the working of the human brain, see AlKhalili and McFadden (2014:324ff). The logic gates of a computer are similar to Khalili and McFadden (2014:324ff.). The logic gates of a computer are similar to neurons. 'So, if the neuron is like a logic gate, then brain, made up of billions of neurons, might be thought of as some kind of computer; or at least, this is the assumption of most cognitive neuroscientists who subscribe to what is called computational theory of mind' (Al-Khalili \& McFadden 2014:330). Nevertheless, highly connected computers such as the worldwide web are not conscious like the human brain. 
the free market system, there is freedom to move freely between a variety of processors.

\section{Critique of technology}

The kind of reality brought to the fore by modern technology, according to Heidegger (1977:20-21), is called Enframing (Ge-stell). It refers to the way we reduce the essence of nature to the wealth it offers when transformed by human technology. Enframing reveals the essence of technology as standing reserve (hoarding). The earth, for example, reveals itself as a coal-mining district, and soil as a mineral deposit. What is unlocked (mined) is transformed (refined), what is transformed is stored up (packaged), what is stored up is, in turn, distributed (commercialised) and what is distributed is switched about ever anew (endless cycle) (Heidegger 1977:14-17). What is real - being - is thus transformed into and revealed as standing reserve. Human becomes part of this standing reserve (objectification), as a resource esteemed only for his or her potential contribution to the technological process (Heidegger 1977:27). In the present we have added data to the hoarding process, which is enabled by the storage capacity of computers. Human value relates to its statistical value in the hoarding, processing and use of data.

While technology is the logical outcome of human's desire for self-assurance, for submitting everything to himself or herself, it has come to dominate him or her. Humans have become helplessly caught up in the 'total mobilisation' that technology requires if it is to press ahead (Cooper 1996:65). Technology has thus become the process by which machines alter our existence. Human has become self-estranged. In Heidegger's (1977:27) words, man does not today any longer encounter himself, that is, his essence.

The loss becomes clear when Heidegger (1977:34) considers what techné was in the time of the early Greek philosophers. In Greece, the arts soared to supreme heights through the way it revealed being and meaning. Art [techné] brought the presence [Gegenwart] of the gods, and the dialogue of divine and human destinies to radiance. Art was manifold in meaning. It was pious, yielding to the holding sway and the safekeeping of truth.

\section{Being in light of artificial intelligence}

What it is to be human cannot be answered without addressing being anew. The question of being has been addressed in the past, especially in an ontological and existential manner. Presently, the question of being must be related to $\mathrm{AI}$ and the movement towards a kind of 'conscious materialism'. In AI, dead material, lifeless objects, becomes alive. We breathe intelligence and consciousness (the breath of life) into silicon (see Gn 2:7). Artificial intelligence is a modus of being that questions (being) in a new way because it entails a different kind of species as well as a possible different kind 'humanity' through the merging of human and machine intelligence (androids). It also questions our understanding of material objects, of non-human, machine intelligence. To talk of any object implies a human subject. The human subject can be seen also as object. The subjectobject interaction is called symmetrical realism by Smith (1996:85) by which he understands metaphysical preconditions for the existence of objects as well as some preconditions for the existence and nature of subjects. Realism implies immanence, but does not exclude some form of transcendence. No realism is expressed in some form of constructionism that may change in tandem with new understanding. Smith (1996:91) appreciates anti-foundational and postmodern critique because science (and its focus of objectivity) is also '... a product of social institutions and political power as literature or art, and cannot be understood in a "purely objectivist" manner'.

We continually grapple with the question of being in light of a new understanding of reality. Being recedes as our understanding of reality 'changes'. Being [das Sein] is the most common concept and simultaneously the most empty concept that resists definition (Heidegger 1976:2). The generality of the concept transcends any categorical generality. ${ }^{5}$ The generality of being does not mean that it is transparent to understanding. On the contrary, being is the darkest concept we have (Heidegger 1976:3). With this notion of being, Heidegger brought a correction to the illusion of clear and certain knowledge (knowledge of being) springing from the enlightenment.

The natural sciences are founded on the enlightenment idea of certainty. From the empirical and particular realm, science moves the universal (universality of laws). This is a transposition to the transcendent (science cannot operate without the transcendent). Smith (1996:155) says in this regard, '[f]ar from being universal, the physical world is a realm of complete and total particularity'. Once we abandon this particularity, we enter into metaphysics.

The question of being is linked to that of meaning. ${ }^{6}$ Humans cannot live without meaning. It can be argued that the way we impose meaning on the world defines our understanding of meaning. The fact that we keep on doing so underscores the notion that the meaning of being is a time- and culture-dependent construct. This relates to the existential design of life. Heidegger described human being in its worldliness in a specific time (Zeitlichkeit 1976:231) and space (Die Räumlichkeit 1976:102-113). We are 'thrown' in the world (Geworfenheit 1976:175), with its objectivity (Welt as res extensa 1976:89, Zuhandenen 1976:102), historicity which implies our existentiality with its fear (Angst 1976:184) and care (Sorge 1976:191). We are entangled with the world and things. Being comes to us calling to care (Ruf der Sorge 274).

5."Die "Allgemeinheit" des Seins "übersteigt" alle gattungsmässige Algemeinheit" (Heidegger 1976:3)

6.No ontology is possible without answering the question of meaning. Ontology is blind if not founded on meaning. Heidegger (1976:11) formulates: 'Alle Ontologie .. bleibt im Grunde blind ....wenn sie nicht zuvor den Sinn von Sein zureichend geklärt und diese Klärung als ihre Fundamentalaufgabe begriffen hat'. 
Being cannot be revealed in isolation from human beings. This implies that the nature of reality conforms to the nature, culture and self-understanding of humans. Because this is not one, being cannot be one. This implies the artificial nature of reality as human construct. Humans struggle to deal with uncertainty and their religions, sciences ${ }^{7}$ and metaphysical systems endeavour to overcome this.

Illusion is linked to mimesis. Intelligent machines (robots) will act 'as if...' they are human. They emulate the human. If this is all an illusion, it begs the question of human authenticity. We also imitate and emulate ideals in constructed 'as if' realities. Our culture, knowledge and religion can simply be seen as a construct that will change in time. Being itself can only be grasped within the constraints of our time and our special way of understanding the world. Is being illusion? Is the world an illusion? Gabriel argued so in his 2015 publication, Why the World Does Not Exist. He rejected metaphysics as the theory of everything (see Gabriel 2017:loc. 1219 of 6449). One could also aver that consciousness is an illusion and that the 'real' world is always different from the way we experience it - but the world as illusion refers to certain absolute vantage points where we claim to know on an abstract, conceptual and universal level what cannot be proven.

Gabriel comes to a middle position which he calls New Realism, built on the idea that we can actually grasp reality as it is in itself by way of our mental faculties (Gabriel 2017:loc. 522 of 6449). But this is perspectival: ' $n$ ] evertheless, there is a reality, of course. It cannot be directly experienced, but it can be isolated by considering it from various vantage points' (Gabriel 2017:loc. 513 of 6449). These 'vantage points' may be credible from a natural scientific and empirical perspective, but these perspectives never convey the complete picture. Humans are neither merely irrational nor merely rational, but 'being(s) which create self-images that can prove to be illusory and cultivates them in concert with others, changing them if they turn out to be harmful' (Gabriel 2017:loc. 2200 of 6449).

The human mind may harbour many illusions. But this does not render everything deceptive. Koch (quoted in Weker 2015:150) distinguishes six ways of understanding human consciousness, namely, consciousness as immaterial soul (Plato, Karl Popper and John Eccles); consciousness as enigmatic because of its immense complexity (Nagel and McGin); consciousness as illusory (Markus Gabriel), the laws governing consciousness still to be developed (Penrosee and Chalmers); consciousness as related to human behaviour (Merleu-Ponty and Gibson) and consciousness as supervenient on brain physicality (Koch).

The software-hardware metaphor applied to the human brain constitutes a dualism. The human mind is biologically, culturally and environmentally integrated. The human mind does not simply supervene on brain physicality. Mind supervenes on brain and body. Ninety-five per cent of consciousness is on a subconscious level and we do not know the mechanisms responsible for consciousness. Machine consciousness, if it becomes possible, will not operate in a similar way because intelligent machines would not need subconsciousness as humans do and we cannot possibly know what difference subconsciousness makes in being human.

Consciousness operates in tandem with human memory. Leibniz has based consciousness on memory (Weker 2015:151). The pivotal role of memory in human consciousness has been captured by Marcel Proust's saying, 'we remember the present and live in the past' (see Proust 1949:108, 120-121, 193). We live in the now, but how long is 'now'. We are often not in the 'now', but in the past or occupied with future tasks. Intelligent machines would not remember. They need not because all information is immediately present.

This cannot possibly imitate human memory, which is always changing in light of new experiences we have made that influence the way we recall the past. We remember differently than computers recall the exact same item (bit) every time.

To understand the difference between human and machine intelligence, we must first know what life is as well as what it means to be human and then decide to which extent machine consciousness would be life and similar to what it means to be human. Humans are more than information processing machines. All life depends on information interchange, which means a constant awareness of the outside and inside environment, where inside environment represents bodily needs and processes and in higher species emergent properties of mind.

Barbour (1999:264) has indicated that human socialisation takes a lifetime to develop and is never complete. While information processing in computers can be done rapidly, machine learning in relation to its environment is much more complex and will take time, similar to human learning. Barbour (1999:266) stresses the importance of the community context: ' $[e]$ vents in the human mind are dependent on cultural contexts that extend far beyond the individual'. He nevertheless believes that if consciousness in computers becomes possible, it would be similar to adult human consciousness.

Interacting with a machine in the so-called 'Chinese room' can fool us in thinking that it is a human, but this is far removed from real life. Gabriel (2017:87) refers to a robot that correctly utters a true statement like the colour of a dice is blue. 'But, since it has no experience of blue at all, something essential would be missing from its perception, namely consciousness'.

\section{Machine consciousness}

Technological development seems to reach its apex in conscious machines. ${ }^{8}$ Kurzweil (2005:29) in his optimism 8 .For a comparison between that human brain and a computer, see Kurzweil (2005:149-153). 
foresees that the whole universe will be saturated with our intelligence.

For computers to be able to interact with humans on a personal level, they need to have a sense of self and would be able to argue with humans, understand human feelings and emotions and respond with sympathy. If a computer does not have emotions similar to that of humans, it would not be able to imitate humans. This would require that computers become much more than algorithm calculating machines.

One of the main issues in creating intelligent machines concerns machine freedom. Machines still depend on humans for production, upgrades and maintenance. The possibility cannot be excluded that self-thinking machines can determine their own developmental history. Computers will then be coding and improving themselves, changing their own architecture. The theme is addressed by many science-fiction films, depicting an eventual machine takeover of the world. Machines may indeed do a better job than humans in issues concerning politics, conflict mediation, war and ecological sensitivity. The absence of human emotions like anger, fear and jealousy eliminates the error margin of intelligent machines.

'Only in advanced life-forms are data from brain cells integrated in the high-level stream of consciousness we call mind' (Barbour 1999:276). Atoms remain the same except for the indeterminacy of quantum events, while a cell represents integration at a much higher level than that of an atom. It is only on the higher level of invertebrates that an elementary level of sentience emerges in news form of memory, learning, anticipation and purposiveness (Barbour 1999:267). In humans we have a total new level of intelligence, intentionality and interaction with the outside world. According to Barbour (1999:278-279), consciousness and mind display new properties with a high level of complexity. These potentialities were built into the lower level components from the beginning.

Machines even 'conscious' ones, if they become possible, will not have these properties (consciousness and mind). Thinking machines will not have the subconscious complexity that characterises humans. Their consciousness will be something totally different from human consciousness.

According to Harari (2015:419), techno-humanism will replace liberal humanism. What happens in the AI debate is that some human characteristics are isolated and duplicated in machines like intelligence. Machine intelligence is accepted as an imminent reality. But it is not human intelligence. Human consciousness presupposes intelligence, but intelligent machines do not imply consciousness. Similarly, the capacity for information storage and data processing does not imply knowledge or wisdom. Knowledge and wisdom presuppose a sense of self. To have a sense of self presupposes a personal history, cultural environment, a sense of belonging to a specific group, speaking a specific language and having specific values. We are not born with values, but acquire them through experience. Values cannot simply be programmed. The way they influence most of our thinking and actions on a subconscious level is dynamic and complex.

\section{Interaction between human and artificial consciousness}

Although we are years away from ASI, researchers predict that the leap from AGI to ASI will be a short one.

No one really knows when the first sentient computer life form is going to arrive. But as ANI gets increasingly sophisticated and capable, we can begin to envision a future that is driven by both machines and humans - one in which we are much more intelligent, conscious and self-aware. We use technological instruments to extend our bodies. Machines can do what humans cannot do and vice versa. Technology enables us to enhance our vision, sight and mobility, and replace body parts with prostheses.

These technological artefacts have predominantly been limited to bodily functions. Humans identify with these artefacts as part of their bodies. Now we will, for the first time, be able to significantly enhance the human mind. On the menu is the possibility of tapping into the Internet, getting instant access to information stored on the Internet and participating in 'cloud-computing'. We do not really know how this will affect human consciousness because the impact will only become known when we realise these functions.

We understand ourselves by comparison. One standard comparison is with animals. Humans, unlike animals, are unique in enjoying a sense of self, having self-reflection and being self-critical. Comparing ourselves to animals has always been to signify human uniqueness and superiority. Animals are aware of their environment and some species may have a limited form of consciousness, but a sense of self does not exist. Will conscious machines have a sense of self? We get attached to our pets and often they become one with a family. Our pets become attached to us as well, although we cannot determine the depth of this attachment. Will we get similarly attached to machines in our lives, especially if they display some form of intelligence and self? Attachment implies mutual interaction between parties involved. ${ }^{9}$ In comparing ourselves with intelligent machines, the situation is reversed as machines will soon exceed human intelligence.

Like most technologies, $\mathrm{AI}$ is a double-edged sword. If the technological singularity happens, then there would not be a machine takeover. Instead, we will be able to co-exist with AI

9.Lumbreras (2017:160) refers to the film Her where a human falls in love with an operating system, which has been designed to please the recipient. It displays operating system, which has been designed to please the recipient. It displays emotion, but this is artificial and not real. In this way, the recipient is fooled to experience a 'true' relationship. Lumbreras (2017:163) correctly states that 'human beings tend to value the subjective states of their partners in these interactions as much as their own, and understand that if these states are missing, then thei partners are faking in a relationship and that is not authentic'. If empathic androids could become conscious and experience true subjective states, they would b entitled to the same dignity and rights that humans enjoy (Lumbreras 2017:165). 
in a world where machines reinforce human abilities. In Kurzweil's words (2005):

Most important, the intelligence that will emerge will continue to represent the human civilization, which is already a humanmachine civilization.... Our civilization will remain humanindeed, in many ways it will be more exemplary of what we regard as human than it is today, although our understanding of the term will move beyond its biological origins. (p. 30)

Kurzweil (see his six epochs 2005:14-21) predicts that by 2045 we will be able to multiply our intelligence a billion-fold by linking wirelessly from our neocortex to a synthetic neocortex in the cloud. This will essentially cause a melding of humans and machines. Not only will we be able to connect with machines via the cloud, but also we will be able to connect to another person's neocortex. This could enhance the overall human experience and allow us to discover various unexplored aspects of humanity.

We are entering the age of conscious materialism. Materialism was always viewed negatively, from a Christian perspective, which was influenced by neo-Platonist negativity towards the body and material things. We have now a more positive view on the body. We know now that mind depends on brain and spirituality is not possible without the material, without bodily physicality. The question is to what extent a spiritual materialism is possible and what it means. Spiritual materialism comes to the fore in a new perception of our planet as a living entity (Gaia), with new notions of Panpsychism (read Panconsciousness), in human-machine interaction and with notions of the universe as something conscious and alive. The 'universemetaphor' seems to replace God. It comes to the fore in sayings like 'my fate is in the hands of the universe; the universe will decide; the universe will restore balance'. Spiritual materialism may assume a new meaning in the context of human-machine interaction, especially when we start to interact with machines on interpersonal level. The experience of transcendence is not possible without the immanent reality of bodies, objects and things, and we always return to immanent reality after transcendent encounters.

\section{Conclusion}

We must critically embrace computer evolution. Computers have become part of human life and its undoubtable advantages will irrevocably change human life. I do not believe that the so-called techno-religion will be a threat to religion. Religion is simply too unique to be replaced by power-promising machines. I doubt that machines will be able to replace real interpersonal relations, not to mention believers' relationship with God.

Being will be reinterpreted as was the case up until now in human history. Being will attain a new dimension when human-machine interaction becomes pivotal. Conscious materialism will extend the challenges of being as well as our understanding of our place in the universe.
What it means to be human is uniquely a human phenomenon. It is precisely human vulnerability and notions like emotion, desire, dependence, sin, hope and mortality that make us human. Human greatness is characterised by human's interaction with transcendence. Being self-transcending beings makes us more than any well-programmed machine. We are 'programmed' to live towards the future, expecting more, always beginning afresh and dreaming about new possibilities. This is what characterises being as ineffable. In the mode of luring ineffability, being enfolds humans in its special dynamism.

\section{Acknowledgements}

Many thanks to Professor Wessel Bentley, who assisted in the finalisation of this article's publication on behalf of the late Professor Cornel W. du Toit, providing feedback on editorial queries and guiding any necessary changes.

\section{Competing interests}

The author declares that they have no financial or personal relationships which may have inappropriately influenced them in writing this article.

\section{Author's contributions}

C.W.d.T. is the sole author of this research article.

\section{Ethical considerations}

No ethical clearance was required for this study.

\section{Funding information}

This research received no specific grant from any funding agency in the public, commercial or not-for-profit sectors.

\section{Data availability statement}

Data sharing is not applicable to this article as no new data were created or analysed in this study.

\section{Disclaimer}

The views and opinions expressed in this article are those of the authors and do not necessarily reflect the official policy or position of any affiliated agency of the authors.

\section{References}

Al-Khalili, J. \& McFadden, J., 2014, Life on the edge: The coming of age of quantum biology, Dreamscape, Birmingham.

Barbour, I., 1999, 'Neuroscience, artificial intelligence, human nature', in R.J. Russell, N. Murphey, T.C. Meyereing \& M.A. Arbib (eds.), Neuroscience and the person, pp. 361-398, The University of Nortre Dame Press, Notre Dame.

Bostrom, N., 2014, Superintelligence: Paths, dangers, strategies, Oxford University Press: Oxford.

Fuller, M., 2017, 'Boundless riches: Big data the Bible and human distinctiveness', in M. Fuller (series ed.), Issues in science and theology: Are we special?, pp. 181-189, Springer, Cham, Switzerland.

Gabriel, M., 2015, Why the world does not exist, Polity Press, Cambridge, UK. 
Gabriel, M., 2017, I am not a brain. Philosophy for the twenty-first century, Polity Press, Cambridge, UK.

Gartner, 2018, Gartner identifies five emerging technology trends that will blur the lines between human and machine, viewed 20 August 2018, from https://www. gartner. com/en/newsroom/press-releases/2018-08-20-gartner-identifies-five-emergingtechnology-trends-that-will-blur-the-lines-between-human-and-machine.

Harari, Y.N., 2015, Homo Deus. A brief history of tomorrow, Harvill Secker, London.

Heidegger, M., 1976, Sein und zeit, Max Niemeyer, Tübingen.

Heidegger, M., 1977, The Question concerning technology and other essays (Die Technik und die Kehre; Holzwege; Vortäge und Aufsätze), trans. W. Lovitt, Garland Publishing Inc., New York.
Kurzweil, R., 2005, The singularity is near. When humans transcend biology, Penguin, New York.

Lumbreras, S., 2017, 'Strong artificial intelligence and imago hominis: The risk of a reductionist definition of human nature', in M. Fuller (series ed.), Issues in science and theology: Are we special?, pp. 157-168, Springer, Cham, Switzerland.

Proust, M., 1949, The captive. Part one, Chatto \& Windus, London.

Smith, B.C., 1996, On the origin of objects, MIT Press, London.

Weker, M.M., 2015, 'Life and consciousness: Is there a biological foundation for consciousness', in D. Evers, M. Fuller, A. Jackelén \& K.W. Saether (eds.), Issues in science and theology: What is life?, pp. 149-156, Springer, Halle/Saale. 